\title{
RESPOSTA DE CULTURAS À APLICAÇÃO DE CALCÁRIO EM SUPERFÍCIE OU INCORPORADO AO SOLO EM CAMPO NATIVO
}

\author{
LIMING SUPERFICIAL AND INCORPORATED ON SOIL \\ UNDER NATIVE SOD AND CROPS YIELD
}

\author{
João Kaminski ${ }^{1}$ Danilo dos Santos Rheinheimer ${ }^{2}$ Edilceu João Silva Santos ${ }^{3}$ Luciano Colpo Gatiboni $^{3}$ \\ Edson Campanhola Bortoluzzi ${ }^{3}$ Flávio Moreira Xavier ${ }^{4}$
}

RESUMO

Convencionalmente, os solos sob campo nativo são revolvidos para a incorporação do calcário e implantação das culturas produtoras de grãos. Este trabalho avaliou a resposta de culturas ao calcário aplicado na superfície e incorporado em solo originalmente sob campo nativo. $O$ experimento foi conduzido na área Experimental do Departamento de Solos da Universidade Federal de Santa Maria (RS), num Argissolo Acinzentado Distrófico plíntico. Os tratamentos foram $O, 2,8,5$ e $17 \mathrm{Mg}$ há $^{-1}$ de calcário incorporado e em superfície. Usou-se o delineamento experimental, blocos ao acaso, com quatro repetições. Cultivaram-se milho (94/95 e 96/97), azevém (95, 96 e 97) e soja (95/96 e 97/98). As culturas de milho, azevém e soja produziram satisfatoriamente na área de campo nativo não revolvida e sem calcário, porém o revolvimento do solo, sem a correção da acidez, ocasionou menores rendimentos. A aplicação do calcário na superfície, em dose menor ou igual a 1/2 SMP para $\mathrm{pH}$ 6,0, proporcionou maiores rendimentos de grãos de milho e de soja do que quando o calcário foi incorporado ao solo, o que não ocorreu com o azevém.

Palavras-chave: acidez, canais naturais, matéria orgânica.

\section{SUMMARY}

In conventional tillage system the soils under native sod are revolved for lime incorporation and crop production. The objective of this study was to evaluate the effects of surface and subsurface liming in soil under native sod. The experiment was conducted at the experimental field of the Soil Science Department, at the Federal University of Santa Maria, RS, Brazil, on a Argissolo Acinzentado Distrófico plíntico soil, médium texture, with high potential acidity (Plinthaquult), under native sod. Lime rates o/O, 2, 5.5 and $17 \mathrm{Mg}$ ha' were used. On half of the plots the lime was mixed with the topsoil by disk plow. Lime was left on the surface on the other half of the plot. The crops used were com (94/95 and 96/97), ryegrass (95, 96 and 97) and soybean (95/96 and 97/98). The yield of the plants were considered high on acid soils under native sod. Plowing on the acid soil without application of lime decreased yield culture. Com and soybean yields for the two lowest liming rates were higher with surface applied lime. Subsurface applied lime, however was beneficiai for ryegrass.

Key words: acidity, chamei piam, organic matter.

\section{INTRODUÇÃO}

Estima-se que existam no Estado do Rio Grande do Sul, aproximadamente, 15 milhões de hectares de campo nativo, cuja maioria vem sendo utilizada com a pecuária de corte (PÖTTKER, 1995a). A maioria desses solos apresenta condição edáfica que permite incorporá-los no processo de produção de grãos, ou de pastagem cultivada. No entanto, são geralmente ácidos e possuem baixos teores de fósforo, o que deve ser adequadamente tratado para aproveitar o seu potencial. Por outro lado, têm altos teores de matéria orgânica e boa estruturação física, o que permite armazenamento de água e aeração adequados, favorecidos, ainda, pela

\footnotetext{
${ }^{1}$ Engenheiro Agrônomo, Doutor, Professor, Departamento de Solos, Universidade Federal de Santa Maria (UFSM). Bolsista CNPq.

${ }^{2}$ Engenheiro Agrônomo, MSc. em Agronomia, Biodinâmica de Solos, Professor do Departamento de Solos, UFSM, CP 221, 97105-900,

Santa Maria - RS. E-mail: danilo@ ccr.ufsm.br. Autor para correspondência.

${ }^{3}$ Engenheiro Agrônomo, MSc. em Agronomia, Biodinâmica de Solos.

${ }^{4}$ Engenheiro Agrônomo, Professor aposentado, Departamento de Solos, UFSM.
} Recebido para publicação em 19.03.99. Aprovado em 17.11.99 
presença de redes de canais formados pela decomposição das raízes velhas, e/ou de galerias resultantes da atividade de insetos do solo. Isso pode facilitar o crescimento das raízes, uma vez que apresentam menor resistência física, maior disponibilidade de nutrientes e menor toxicidade de alumínio (GASSEN \& KOCHHANN, 1998). A matéria orgânica pode diminuir a fitotoxidez do alumínio, devido à possibilidade de formar ligações estáveis entre ambos (ERNANI \& GIANELLO, 1982; MYAZAWA et al., 1992; ERNANI et al., 1998), ou ainda manter complexos orgânicos hidrossolúveis na solução do solo, que atuam como agentes complexantes de cátions metálicos, diminuindo sua atividade (MYAZAWA et al., 1992; DRISCOLL \& SCHECHER, 1988). A implantação de culturas comerciais sobre campos nativos ácidos e com baixa disponibilidade de nutrientes, sem o revolvimento do solo, tem sido viável economicamente (PÖTTKER, 1995b). A adição de corretivos de acidez na superfície do solo tem apresentado eficiência similar a sua incorporação ao solo, quanto à produtividade de grãos das culturas comerciais e de produção de forragem, porém, deve ser destacado que a camada superficial do solo sob campo nativo apresenta menores teores de alumínio trocável e maiores teores de cálcio e magnésio e valores de $\mathrm{pH}$, como mostram dados de BEM et al. (1996).

A correção da acidez do solo é realizada pela calagem, que pressupõe a incorporação uniforme do calcário por arações e gradagens; no entanto, o revolvimento do solo tem a desvantagem de destruir os agregados de maior tamanho (FUCKS et al., 1994). Para que ocorra a recuperação da estrutura original, CARGNELUTTI et al. (1997) mostraram que são necessários, aproximadamente, três anos de cultivo no sistema plantio direto (SPD).

Resultados obtidos com o SPD, implantado sobre sistema de cultivo convencional, não têm mostrado respostas importantes à aplicação de calcário, mesmo que com pH 4,5 (em $\mathrm{CaCl}$ $\left.0,01 \mathrm{~mol} \mathrm{~L}^{-1}\right)$ e $32 \%$ de saturação por bases, na camada de 0-20cm (CAIRES et al., 1998). O efeito residual do calcário incorporado no sistema de cultivo convencional pode ultrapassar os vinte anos (AZEVEDO et al., 1996). Então, quando esses solos são submetidos ao SPD, somam-se ao efeito residual do calcário, as menores perdas de corretivo pela erosão e o aumento nos teores de matéria orgânica, aliviando os efeitos deletérios da acidez. Com isso, as reaplicações de calcário podem não ser necessárias, pois são mantidas as altas produtividades de culturas como o milho e a soja, mesmo quando a análise do solo indica necessidade de calcário. Nesse sentido, AMARAL (1998) não observou diferenças na produtividade do milho e na mistura aveia preta+ervilhaca com a reaplicação de calcário, quer na superfície ou incorporado ao solo, após oito anos de SPD. A ausência de resposta ao calcário foi atribuída aos altos teores de fósforo, cálcio e magnésio existentes no solo, em função de aplicações anteriores de calcário e fertilizantes.

O presente trabalho objetivou avaliar a resposta das culturas de milho, soja e azevém à aplicação de doses de calcário na superfície ou incorporado uniformemente com aração e gradagem, em solo sob campo nativo, seguida de adoção do sistema plantio direto.

\section{MATERIAL E MÉTODOS}

O experimento foi conduzido no campo experimental do Departamento de Solos da Universidade Federal de Santa Maria (RS), em solo Argissolo Acinzentado Distrófico plíntico, textura média, relevo suave ondulado, substrato sedimentos recentes aluviais. A área estava recoberta com campo nativo até 1994, quando foi iniciado o experimento. Em outubro de 1994, coletou-se uma amostra composta de solo na camada de $0-20 \mathrm{~cm}$, cujos resultados analíticos foram: $\mathrm{pH}$ em água $=4,4$; índice $\mathrm{SMP}=4,5 ; \mathrm{M} . \mathrm{O} .=37 \mathrm{~g} \mathrm{~kg}^{-1} ; \mathrm{Al}$ trocável = 3,3 e $\mathrm{Ca}+\mathrm{Mg}$ trocáveis $=3,7 \mathrm{cmol}(\mathrm{c}) \mathrm{dm}^{-3} ; \mathrm{P}$ disponível $=2,3 \mathrm{mg} \mathrm{dm}^{-3}$ e $\mathrm{K}$ disponível $=54 \mathrm{mg} \mathrm{dm}^{-3}$.

A vegetação do campo nativo foi dessecada com Glyphosate, na dose de $5 \mathrm{Lha}^{-1}$. As doses de calcário usadas foram baseadas na estimativa da dose necessária para elevar o $\mathrm{pH}$ do solo a 6,0. Os tratamentos consistiram da aplicação superficial e da incorporação do calcário, com uma aração e duas gradagens, nas doses de $\mathrm{O}, 2,0,8,5$ e $17, \mathrm{OMg}$ há $^{-1}$ (l SMP). A mobilização do solo para a incorporação do calcário $(0-20 \mathrm{~cm})$ foi feita na implantação do experimento. A partir desse momento, as culturas foram conduzidas no sistema plantio direto, com dessecação das plantas remanescentes. Aos 24 meses da implantação, no tratamento com adição de $2 \mathrm{Mg}$ há $^{-1}$, reaplicou-se essa dose em superfície, inclusive no tratamento incorporado. $\mathrm{O}$ delineamento experimental utilizado foi o de blocos ao acaso, com quatro repetições. A parcela principal, doses de calcário, mediu 12 x $12 \mathrm{~m}$ e a subparcela, modo de aplicação do calcário, $6 \mathrm{x}$ 12m. Cultivaram-se milho (94/95 e 96/97), azevém (95, 96 e 97) e soja (95/96 e 97/98). Foram adicionados N, P e K (na linha de semeadura) nos cultivos de verão com base nas análises de solo e nas quantidades recomendadas pela Comissão de Fertilidade do Solo do Núcleo Regional Sul de Ciência do Solo (COMISSÃO, 1995). A partir da safra 95/96, os fertilizantes foram aplicados a lanço. 
No azevém não foi feita adubação de base, mas somente nitrogenada de cobertura, parcelada em duas adições de $30 \mathrm{~kg}$ há $^{-1}$, na forma de ureia. Determinou-se a produtividade de grãos do milho e soja e a massa seca da parte aérea do azevém em florescimento pleno.

Coletaram-se amostras de solo (10 subamostras/subparcela) aos 36 meses após a aplicação do calcário, nas profundidades de 0-2,5 e $0-5 \mathrm{~cm}$. As amostras foram secas em estufa a $55^{\circ} \mathrm{C}$ e passadas em peneira de $2 \mathrm{~mm}$. Avaliaram-se o $\mathrm{pH}$ em água, os teores de cálcio, magnésio, alumínio e potássio trocáveis e os teores de fósforo disponível (TEDESCO et al., 1995).

Os valores de rendimento de grãos de milho e soja e de produção de massa seca de azevém foram submetidos à análise de variância. Aplicou-se o teste de comparação de médias Tukey para os modos de aplicação de calcário $(\mathrm{p}<0,05)$.

\section{RESULTADOS E DISCUSSÃO}

Os bons rendimentos de grãos de milho, de soja e produção de massa seca azevém (Tabela 1) obtidos no tratamento sem a aplicação de calcário e sem mobilização do solo, apesar da sua elevada acidez potencial (46\% de saturação com alumínio), podem ser atribuídos à sua boa estrutura e à manutenção das condições naturais existentes, como os canais formados pela decomposição das raízes velhas e à existência de galerias abertas por insetos do solo. Isso pode ter facilitado o crescimento das raízes, aproveitando a menor resistência física e a maior disponibilidade de nutrientes nesses locais, devido à sua circulação com as águas de drenagem, como mostraram GASSEN \& KOCHHANN (1998) em galerias abertas por "coros". Também ao teor de matéria orgânica desse solo, pode estar associada a possibilidade de diminuir a fitotoxidez do alumínio, devido à formação de complexos orgânicos estáveis

Tabela 1 - Rendimento de grãos de milho e de soja e produção de massa seca de azevém após a aplicação de calcário superficial e incorporado em campo nativo

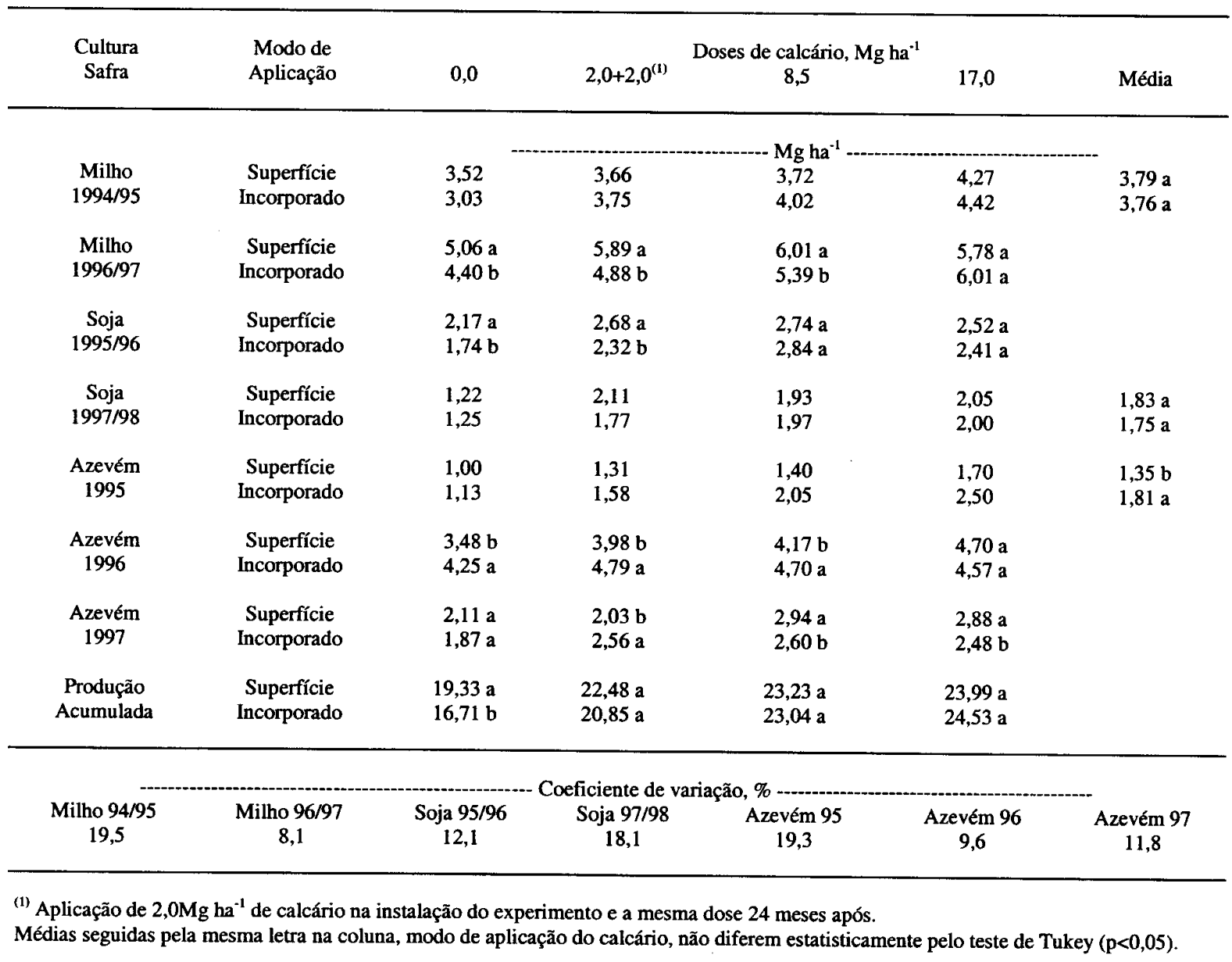

Ciência Rural, v. 30, n. 4, 2000. 
entre ambos na fase sólida (ERNANI \& GIANELLO, 1982; MYAZAWA et al., 1992; ERNANI et al., 1998), ou à presença de complexos orgânicos hidrossolúveis na solução do solo, o que diminui a sua atividade (DRISCOLL \& SCHECHER, 1988).

No tratamento sem calcário e com mobilização do solo, observou-se menor rendimento de grãos de milho em relação ao tratamento sem revolvimento, sendo inferior em 14 e $13 \%$ nas safras 94/95 e 96/97. Também a produção de massa seca do azevém foi inferior em 18 e $12 \%$ nas safras 96 e 97 , e $20 \%$ na de grãos de soja na safra 95/96. O efeito negativo da mobilização do solo deve-se, principalmente, às alterações nas características físicas, agregação (FUCKS et al., 1994) e descontinuidade porosa, uma vez que as características químicas não se alteraram substancialmente (Tabela 2). As diferenças entre os modos de aplicação de calcário foram mais evidentes nas culturas de verão, período em que normalmente ocorrem deficiências hídricas na região, o que toma a planta mais vulnerável aos efeitos deletérios da acidez. No quarto ano, o efeito deletério da aração do solo sem a adição de calcário desapareceu (azevém em 97 e soja em 97/98 Tabela 1), o que pode estar vinculado à recuperação da estrutura original do solo pela implantação do sistema plantio direto, como observado por CARGNELUTTI et al. (1994).

A aplicação de calcário incorporado e superficial, na dose recomendada pela Comissão de Fertilidade do Solo do Núcleo Regional Sul de Ciência do Solo (COMISSÃO, 1995), aumentou em 46 e $21 \%$ na safra 94/95 e, 37 e $14 \%$ na safra 96/97; o de soja aumentou 39 e $26 \%$ na safra 95/96 e 59 e $68 \%$ na safra 97/98; o de massa seca de azevém aumentou 120 e $70 \%$, 35 e $8 \%$, e 33 e $37 \%$ nas safras 95, 96 e 97, respectivamente. Durante o período de avaliação (1994 a 1998), observou-se oscilação das médias do rendimento das culturas, devido às condições edafoclimáticas.

Não houve diferença significativa no rendimento de grãos de milho entre as formas de aplicação de calcário imediatamente após sua aplicação, enquanto na safra 96/97 (24 meses após a aplicação do calcário) houve diferença significativa, pois os rendimentos foram maiores com a aplicação superficial das duas primeiras doses e menor com 17,OMg há ${ }^{-1}$, comparativamente à incorporação com aração e gradagens. Isso se deve à correção de uma parte maior da acidez do solo, onde os valores de $\mathrm{pH}$ e os teores de cálcio e magnésio foram maiores e os de alumínio menores na camada superficial, comparativamente à incorporação (Tabela 2).

\begin{tabular}{|c|c|c|c|c|c|c|c|c|}
\hline \multirow{3}{*}{$\begin{array}{l}\text { Superficial } \\
\text { Incorporado }\end{array}$} & \\
\hline & 4,6 & 5,6 & $6,0^{\circ}$ & 6,3 & 4,5 & 5,3 & 5,8 & 6,0 \\
\hline & 4,7 & 5,4 & 5,5 & 5,6 & 4,5 & 5,0 & 5,1 & 6,2 \\
\hline & \multicolumn{8}{|c|}{ Alumínio trocável, $\mathrm{cmol}_{(\mathfrak{c})} \mathrm{dm}^{-3}$} \\
\hline \multirow{3}{*}{$\begin{array}{l}\text { Superficial } \\
\text { Incorporado }\end{array}$} & 2,2 & 0,1 & 0,0 & 0,0 & 3,0 & 0,3 & 0,0 & 0,0 \\
\hline & 2,5 & 1,2 & 0,4 & 0,0 & 3,3 & 0,6 & 0,5 & 0,0 \\
\hline & \multicolumn{8}{|c|}{ Cálcio trocável, $\mathrm{cmol}_{(\mathrm{c})} \mathrm{dm}^{-3}$} \\
\hline Superficial & 3,2 & 6,0 & 7,0 & 8,2 & 3,0 & 5,1 & 6,2 & 8,0 \\
\hline \multirow[t]{2}{*}{ Incorporado } & 2.7 & 4,3 & 5,1 & 5,5 & 2,6 & 4,5 & 4,6 & 4,7 \\
\hline & \multicolumn{8}{|c|}{ Magnésio trocável, $\mathrm{cmol}_{(c)} \mathrm{dm}^{-3}$} \\
\hline Superficial & 1,9 & 3,9 & 4,2 & 4,7 & 1,8 & 3,6 & 4,0 & 4,5 \\
\hline \multirow[t]{2}{*}{ Incorporado } & 1,8 & 3,1 & 3,5 & 3,8 & 1,7 & 3,3 & 3,2 & 4,0 \\
\hline & \multicolumn{8}{|c|}{ Potássio trocável, $\mathrm{mg} \mathrm{dm}^{-3}$} \\
\hline Superficial & 100 & 88 & 91 & 89 & 92 & 71 & 69 & 69 \\
\hline \multirow[t]{2}{*}{ Incorporado } & 103 & 93 & 110 & 110 & 84 & 87 & 93 & 87 \\
\hline & \multicolumn{8}{|c|}{ Fósforo disponível, $\mathrm{mg} \mathrm{dm}^{-3}$. } \\
\hline Superficial & 5,4 & 6,4 & 8,0 & 9,0 & 6,8 & 5,6 & 5,8 & 6,8 \\
\hline Incorporado & 6,4 & 8,6 & 7,0 & 9,0 & 6,1 & 7,6 & 6,4 & 6,0 \\
\hline
\end{tabular}

(1) Dose de calcário aplicado em $\mathrm{Mg} \mathrm{ha}^{-1}$

(2) Aplicação de $2 \mathrm{Mg} \mathrm{ha}^{-1}$ de calcário na instalação do experimento e a mesma dose 24 meses após.
Para a cultura da soja, na safra 95/96, a aplicação superficial de $2, \mathrm{OMg}$ há $^{-1}$ de calcário proporcionou maior rendimento do que quando incorporado ao solo. Nas demais doses e na safra 97/98, as formas de aplicação de calcário se equivaleram. PÖTTKER (1995b) constatou que a incorporação do calcário em campo nativo em um solo com $30 \%$ de argila, apesar de Ter aumentado o rendimento de grãos de soja, não diferiu significativamente da aplicação superficial de calcário no primeiro ano de cultivo. Na avaliação residual do calcário, ocorreu a mesma tendência tanto para o trigo como para a soja. Já em um solo com $60 \%$ de argila, também em campo nativo, a incorporação do calcário proporcionou maior rendimento de grãos 
de soja (primeiro ano) e de trigo (após a soja) em relação à aplicação superficial de calcário.

A produtividade do azevém, cultivado aos seis meses após a calagem, foi maior com a incorporação do calcário, independente da dose utilizada. No segundo cultivo, 18 meses após a calagem, o calcário incorporado manteve maiores rendimentos para as doses de 2,0 e $8,5 \mathrm{Mg}_{\text {há }}{ }^{-1}$. Já no terceiro cultivo, aos 30 meses da calagem, a incorporação do calcário só manteve maiores rendimentos na dose de $2,0+2,0 M g$ há ${ }^{-1} \mathrm{e}$, nas demais doses, a aplicação superficial superou os rendimentos obtidos com a incorporação. A reaplicação de $2, \mathrm{OMg}$ há $^{-1}$ (safra 97) proporcionou maior efeito quando anteriormente o calcário tinha sido incorporado. Isso se deve à correção parcial da acidez até a profundidade de incorporação $(20 \mathrm{~cm})$, em comparação à aplicação superficial, onde esse efeito permaneceu nos primeiros $5 \mathrm{~cm}$ (Tabela 2). A maior resposta do azevém ao calcário, especialmente quando este foi incorporado, deve-se a maior sensibilidade dessa cultura à acidez do solo. MACEDO (1987) verificou que a incorporação do calcário resultou em maior rendimento de massa seca de azevém em comparação à aplicação superficial. No entanto, após o terceiro ano da aplicação do calcário, os rendimentos equivaleramse. PÖTTKER (1995b) verificou que a aplicação de calcário na superfície do solo sob campo nativo resultou em menor rendimento de massa seca de aveia preta, em relação ao calcário incorporado com grade, atribuindo os resultados a um melhor estabelecimento da cultura quando a área foi gradeada.

\section{CONCLUSÕES}

A aplicação do calcário na superfície em dose menor ou igual a 1/2 SMP para $\mathrm{pH} 6,0$ proporciona maiores rendimentos de milho e de soja do que quando o calcário é incorporado ao solo, o que não ocorre com o azevém. A implantação de culturas comerciais (milho, soja e azevém) diretamente sobre o campo nativo em solo ácido é viável, desde que se adicionem corretivos de acidez.

\section{REFERÊNCIAS BIBLIOGRÁFICAS}

AMARAL, A. S. Reaplicação de calcário no sistema plantio direto consolidado. Porto Alegre, RS, 1998. 102p. Dissertação (Mestrado em Ciência do Solo) - Curso de Pósgraduação em Ciência do Solo, Universidade Federal do Rio Grande do Sul, 1998.

AZEVEDO, A.C., KÄMPF, N, BOHNEN, H, Alteraç̃es na dinâmica evolutiva de latossolo bruno pela calagem. Revista Brasileira de Ciência do Solo, Campinas, v.20, n.2, p. 191 $198,1996$.

BEN, J.R., FONTANELI, R.S., PÖTTKER, D. et al. Efeito de modos de aplicação de calcário sobre a produção de aveiapreta em sistema de plantio direto em campo nativo, $\mathrm{m}$ CONGRESSO BRASILEIRO DE PLANTIO DIRETO PARA UMA AGRICULTURA SUSTENTÁVEL, 1, 1996 Ponta Grossa, PR. Anais ... Ponta Grossa : IAPAR-PRP/PG, 1996. p.70-71.
CAIRES, P.E., CHVEIRI, A.W., MADRUGA, E.F. Alterações de características químicas do solo e resposta da soja ao calcário e gesso aplicados na superfície em sistemas de cultivos sem preparo do solo. Revista Brasileira de Ciência do Solo, Campinas, v.22, n.1, p.27-34,1998.

CARGNELUTTI, A.F., REINERT, D.J., BORGES, D.F. Recuperação da estabilidade estrutural induzida pelo plantio direto, de solo que recebeu preparo convencional por dois anos. In: CONGRESSO LATINO-AMERICANO DE CIÊNCIA DO SOLO, 13,ÁguasdeLindóia, 1996 Trabalhos... Campinas: Sociedade Brasileira de Ciência do Solo, 1996. (CD Rom, comissão 6, trabalho 81).

COMISSÃO DE FERTILIDADE DO SOLO - RS/SC Recomendações de adubaçâo e calagem para os estados do Rio Grande do Sul e Santa Catarina. 3 ed. Passo Fundo: SBCS - Núcleo Regional Sul/EMBRAPA/CNPT, 1995. 224p.

DRISCOLL, C.T., SCHECHER, W.D. Aluminium in lhe environmental. In: SIEGEL, M., SIEGEL, A. (eds). Metal ions en biological systems. Aluminium and its role in biology. Basel: Mareei Dekker, 1988. v.24,cap.2,p.59-122.

ERNANI, P.R., GIANELLO, C. Diminuição do alumínio trocável do solo pela incorporação de esterco de bovinos e camas de aviário. Revista Brasileira de Ciência do Solo, Campinas, v.7, n.1, p.161-165, 1982.

ERNANI, P.R., NASCIMENTO, J.A.L., CAMPOS, M.L., $\boldsymbol{e}$ t al Diminuição da toxidade de alumínio para o milho pelo aumento do fósforo no solo. to: REUNIÃO SUL BRASILEIRA DE CIÊNCIA DO SOLO, 2, 1998, Santa Maria, RS. Resumos expandidos... Santa Maria : SBCS Núcleo Regional Sul, 1998. p.153-154.

FUCKS, L.F., REINERT, D.J., CAMPOS, B.C. et al. Degradação da estabilidade estrutural pela aração e gradagem de solo sob plantio direto por quatro anos. In: REUNIÃO BRASILEIRA DE MANEJO E CONSERVAÇÃO DO SOLO E DA ÁGUA, 10, 1994, Florianópolis, SC. Ánais... Florianópolis : SBCS, 1994. p.196-197.

GASSEN, D.N., KOCHHANN, R.A. Benefícios de insetos de solo sob plantio direto. In: NUERNBERG, N.J. (ed.). Conceitos e fundamentos do sistema plantio direto. Lages: SBCS - Núcleo Regional Sul, 1998. cap.9, p.151-160.

MACEDO, W. Efeito de níveis de fósforo com e sem calcário em pastagem de gramíneas e leguminosas. Bagé: EMBRAPA/CNTPO, 1997. Coletânea das pesquisas forrageiras: p.255-272.

MIYAZAWA, M., CHIERICE, G.O., PAVAN, M.A. Amenização da toxidade de alumínio às raízes do trigo pela complexação com ácidos orgânicos. Revista Brasileira de Ciência do Solo, Campinas, v.16, n.2, p.209-215, 1992.

PÖTTKER, D. Correção da acidez de solo no sistema plantio direto. ta: SEMINÁRIO INTERNACIONAL DO SISTEMA PLANTIO DIRETO, 1, 1995, Passo Fundo, RS. Resumos... Passo Fundo : EMBRAPA-CNPT, 1995a. p.15-19.

PÖTTKER, D. Calagem em solos sob plantio direto e em campos nativos do planalto médio gaúcho, to: SÁ, J.C. de MORAES (Coord.). Curso sobre manejo do solo no sistema plantio direto. Castro : Fundação ABC, 1995b. Cap.5,p.202-243.

TEDESCO, M.J., GIANELLO, C., BISSANI, C. et al. Análise de solo, plantas e outros materiais. 2 ed. Porto Alegre: Departamento de Solos - Universidade Federal do Rio Grande do Sul, 1995. 174p. Boletim Técnico, 5. 